\title{
Regionalism and Incentives for Multilateralism
}

\author{
Soamiely Andriamananjara* \\ U.S. International Trade Commission
}

\begin{abstract}
The paper studies the effects of regional integration on the incentives of mem bers and non-members to under take multilateral trade liberalization. Using a three-country political economy model with imperfect competion, it shows how regionalism can undermine support for multilateralism. Discriminatory trade policies alter the balance of gains and losses that members and non-members experience from multilateral liberalization. As the degree of preference within the PTA increases, the member countries' support for large multilateral tariff cuts, as well as the excluded countries' support for small multilateral trade liber alization, declines.(JEL Classifications: F02, F 12, F 15, F 13) ४Key Words:
\end{abstract} Regionalism, M ultilateralism, Trade Liberalization>

\section{Introduction}

The number of Preferential Trade Arrangements (PTA) has increased at a brisk pace during the past two decades. Nearly all WTO's members are

\footnotetext{
* Correspondence Address: Research Division, Office of E conomics, U.S. International Trade Commission, 500 E Street SW, Washington, D.C. 20436, U.S.A., (Tel) 1-202-2053252, ( F ax) 1-202-205-2340, (E-mail) sandriamana@usitc. gov. The findings, interpretations and conclusions expressed in this paper are entirely those of the author and do not necessarily represent the view of the US International Trade Commission or any of its individual Commissioners.
}

(C2000 - Center for International E conomics, Sejong Institution. All rights reserved. 
now party to at least one agreement. Because of their discriminatory and preferential nature, trading blocs can be welfare reducing for the excluded countries, for the participating countries, as well as for the world as a whole since they divert resources away from their most efficient uses (Viner, [1950]). A global trading system divided into a number of competing trading blocs is surely inferior to global free trade. It is therefore perfectly legitimate to wor ry about whether the current wave of regionalism would generate forces that would slow down efforts to liberalize the multilateral trading system. This is the type of issue that is dealt with in the so-called "Regionalism versus M ultilateralism" debate. ${ }^{1}$ So far, the debate has not offered any unequivocal answers as to whether regional integration disposes countries to participate actively in global liberalization.

Two directions are usually considered in this debate. The first direction the "endogenous bloc expansion" literature - is to determine whether PTAs have a tendency to merge or to expand their membership, and whether this tendency will continue so as to eventually yield global free trade. Papers by Baldwin [1995], Yi [ 1996], B ond and Syropoulos [1996] and Andriamananjara [1999] belong to this category.

A second direction-the "endogenous protection" literature-is to study the effects of the establishment of the PTA on the member countries' trade policies with respect to the outsiders. Since the present paper addresses this second issue, and in order to put its contributions into the right context, it is useful to briefly review the existing works dealing with this topic. As Winters [1996] argues, in a survey of this literature, whether PTAs hamper or spurs multilateral trade liberalization is still a relatively open debate.

Extending the M eade model of preferential trading to allow for endogenous lobbying, Panagariya and Findlay [1996] show how preferential trading (a FTA more so than a CU) can lead to increased lobbying for protection against non-members. Krishna [1998] uses a three-country oligopolisticcompetition model to show that a PTA between two countries reduces the incentives to liberalize tariffs reciprocally with the third country. He also demonstrates that, given sufficient trade diversion, multilateral liberalization

1. Bhagwati and Panagariya [1996] and Winters [1996] provide excellent surveys of the literature on this subject. 
that was feasible before the PTA cease to be so afterwards. Cadot, de M elo and Olar reaga [1996] show, using an extension of Grossman and Helpman [1995], that the deepening of an existing regional arrangement can lead to rising protection against non-member imports and thus move the trading system away from multilateralism. In a median voter model, Levy [1997] argues that regional blocs neither hinder nor promote global free trade in an Hecksher-O hlin framework, but undermine the political support for multilateral free trade in an increasing-returns-to-scale framework if the blocs offer disproportionately larger gains to agents in the integrating countries. He wrote: "Bilateral free trade can never increase political support for multilateral free trade." Finally, in a trigger-strategy framework, Bagwell and Staiger [1997] find that the formation of a RIA will initially be accompanied by a "retreat" from multilateral policies but in the longer run, these liberal policies can be restored.

At the other end of the debate, Wei and Frankel [1996] build a model where regional blocs may work as a stepping stone toward global free trade. In their model, regionalism can make, previously unfeasible, global free trade feasible by dividing the original opposition force. Cadot, de M elo and Olar reaga [1998] argue that regional arrangements can help sustain multilateralism, especially FTAs with selective liberalization and rules of origin that allow members countries to compensate losers from trade liberalization. They also show that such agreement can be both welfare enhancing and politically implementable.

In this paper, we use an approach similar to K rishna [1998] to study the effects of regional integration on the incentives of members and as well as those of non-members to undertake multilateral trade liberalization. We generalize Krishna's model by allowing for intermediate levels of liberalization and by looking at the incentives of the outsiders-two aspects that are usually neglected in the literature. We derive two main results. First, the maximum level of multilateral liberalization for which a PTA member's support increases following the establishment of the PTA declines as the degree of preference within the PTA rises. Second, the higher the degree of preference within the PTA, the higher is the minimum level of multilateral tariff cuts for which support increases (or resistance decreases) in the excluded country. Therefore, regionalism can undermine support for multi- 
lateralism in both member and non-member countries: the range of multilateral tariff cuts for which support increases shrinks both from below and from above as the degree of preference in the PTA increases. In a series of comparative statics exercises, we also show that "small" PTAs-in terms of the number of firms and relative to the rest of the world-are more reluctant to conduct large M TL. However, "small" PTAs-in terms of market size-are more willing to undertake large M TL

The basic model three-country model is presented in the next section. Section III introduces multilateral and preferential liberalization into the model and discusses their effects. Section IV studies the effect of regionalism on the incentives for multilateralism. Section $V$ presents some comparative statics analyses and Section VI concludes.

\section{The Basic Model}

Consider a 3-country ( $X, Y$, and $Z$ ) world. ${ }^{2}$ There are $n_{i}$ firms in Countr y $i$ ( $i=X, Y$, and $Z$ ) and all the firms in the world produce goods that are perfect substitutes for each other. As in Brander and Krugman's [1983] reciprocal dumping model, the markets in the different countries are perfectly segmented so that each firm regards each Country as a separate market and chooses its optimal quantity for each country separately.

Looking first at the demand side, denote $q_{j}^{i}$ the quantity supplied by a firm from Country i to Country j's market so that $Q_{j}=\sum_{i=X, Y, Z} n_{i} q_{j}^{i}$ is the total sales of the good in Country j's market. The aggregate utility in Country $\mathrm{j}$ is assumed to have a quasi-linear form: $U\left(Q_{j}\right)=\left(A_{j} Q_{j}-Q_{j}^{2} / 2\right.$. It follows directly that the consumer price of the good in Country $\mathrm{j}$ can be written as a linear function of the total sales in that country: $P_{j}=A_{j}-Q_{j}$.

On the supply side, denote $t_{j}^{i}$ the specific tariff imposed by Country $j$ on imports from $i$, and $\mathrm{c}$ the constant marginal and average costs of production. The specific tariffs simply add on to the marginal costs of firms, whose effective marginal costs of exports then become $c+t_{j}^{i}$. In each market (or

2. For ease of comparison, Krishna's [1998] model and notations are used in this paper. 
country), the $n_{x}+n_{y}+n_{Z}$ firms act as Cournot players and maximize their profits taking other firms' output as given, and they are choosing their quantities simultaneously. A representative firm from Country i's firm, when choosing the quantity that it would export to Country j, solves the following profit maximizing problem:

$$
\max _{q_{j}^{i}} q_{j}^{i}\left[A_{j}-Q_{j}-\left(c+t_{j}^{l}\right)\right],
$$

which yields the $N$ ash equilibrium output level:

$$
q_{j}^{i}=\frac{\left(A_{j}-c\right)}{n+1}+\frac{\sum_{k=X, Y, Z} n_{n} t_{j}^{k}}{n+1}-t_{j}^{i},
$$

where $n=n_{X}+n_{Y}+n_{Z}$. The corresponding profits for the firm in Country $i$ selling in Country $\mathrm{j}$ are:

$$
{ }_{j}^{i}=\left(q_{j}^{i}\right)^{2}=\left[\frac{\left(A_{j}-c\right)}{n+1}+\frac{\sum_{k=X, Y, Z} n_{k} t_{j}^{k}}{n+1}-t_{j}^{i}\right]^{2} .
$$

M odeling the formulation of trade policy is not always straightforward. However, it is clear and widely accepted that producers are given extra weight and are playing a decisive role in shaping a country's trade policy stance. Due to their large number, consumers usually find it hard to effectively lobby for their desired policies. Following K rishna [1998], we rely on the assumption that the producers' profits play a decisive role in determining a country's trade policies. The gains and losses of domestic producers therefore drive decisions regarding trade liberalization.

\section{Types of Trade Liberalization}

We are interested in two types of trade liberalization. The first one is multilateral trade liberalization (MTL) - the magnitude of which is denoted by $\gamma(0 \leq \gamma \leq 1)$. By $M T L$, we mean a simultaneous non-discriminatory tariff reduction by all countries on imports from all their trading partners. The second type of liberalization is the establishment of a preferential trade arrangement (PTA) between (without loss of generality) Countries $X$ and $Y$ 
which exchange reciprocal tariff preferences of $\alpha$ percent $(0 \leq \alpha \leq 1) .^{3}$ In this paper, we want to determine the effects of preferential trade liberalization (of $\alpha$ percent) between $X$ and $Y$ on the incentives of $X, Y$ and $Z$ to undertake a multilateral trade liberalization (of $\gamma$ percent). In a sense, our exercise is a generalization of Krishna's [1998] paper where he only considers "full" liberalization (i.e., either $\alpha=0$ or $\alpha=1$, and either $\gamma=0$ or $\gamma=1$ ). As will become evident later, allowing for intermediate values of $\alpha$ and $\gamma$ provides a number of additional insights.

The two types of trade liberalization, $\gamma$ and $\alpha$, are introduced in the model in a very simple way. If Country $X^{\prime}$ 's initial M F N tariff is $t_{X}$, then its tariff on its PTA partner $Y$ is $=t_{X}^{Y}=(1-)(1-) \cdot t_{X}$, while its tariff on the non-member $Z$ is $t_{X}^{Z}=(1-) \cdot t_{X}$. Similarly, Country $Y$ 's tariff $t_{Y}^{X}=(1-)(1-) \cdot t_{Y}$, while $t_{Y}^{Z}=(1-) \cdot t_{Y}$. Since Country $Z$ is not part of the PTA and does not give out any preference, $t_{Z}^{X}=t_{Z}^{Y}=(1-) \cdot t z$.

As a simplification, we abstract the analysis from optimal tariff considerations. That is, we hold $t_{x}, t_{y}$ and $t_{z}$ as fixed. This feature is also realistic because blocs' external tariffs are in the real world bound by GATT's Article XXIV. ${ }^{4}$ We can write out the total profits of a representative firm in Country $X$ as a function of the PTA's degree of preference and the magnitude of the $M T L: 5$

3. Under the Enabling Clause of the GATT, developing countries can form PTAs that do not go all the way to internal free trade (i.e., $\alpha$ can be less than 1 ). Even under Article 24, PTAs are typically formed over a long transition period. Article 24 only requires that the transition to a complete FTA or CU be accomplished "within a reasonable length of time."

4. There are other reasons for doing so. First, countries, in practice, rarely choose their tariffs for optimal tariff reasons. Also, optimal tariffs derived in economic models have been shown to be much too high compared to the actual observed levels (Krugman [1991]). It should be noted though that many (especially developing) countries have wide gap between their applied tariffs and the maxima committed to in their formal bindings in the WTO. Hence, they can easily increase their duties without violating any WTO bindings.

5. Country Y's total profits can be written and decomposed analogously. 


$$
\begin{aligned}
{ }_{X}(,)=\left\{\frac{\left(A_{X}-c\right)+\left((1-) n_{Y}+n_{Z}\right)(1-) t_{X}}{n+1}\right\}^{2} \\
+\left\{\frac{\left(A_{Y}-c\right)+\left(n_{Z}-(1-)\left(n_{Y}+n_{Z}+1\right)\right)(1-) t_{Y}}{n+1}\right\}^{2} \\
+\left\{\frac{\left(A_{Z}-c\right)-\left(n_{Z}+1\right)(1-) t_{Z}}{n+1}\right\}^{2} .
\end{aligned}
$$

The first (respectively second and third) term on the right hand side represents the profits that a firm in Country $X$ makes in its own (respectively in $Y$ 's and Z's) market. Different types of liberalization have different effects on the firm's profits. On the one hand, an increase in the degree of reciprocal preference, $\alpha$, between $X$ and $Y$ has two effects on the firm's profits. First, it decreases the profits that the firm makes in its domestic market because $Y$ 's firms become more competitive in that market. This decline is increasing in the number of firms from $Y, n_{Y}$. Second, an increase in preference increases the profits made in the partner's market because it improves market access at the expense of firms from $Y$ and $Z$. This increase is higher, the larger the number of firms from $Y$ and $Z, n_{Y}$ and $n_{Z}$. The attractiveness of preferential liberalization depends on the relative size of these two competing effects. Note that preferential liberalization does not affect the profits made in the excluded country.

On the other hand, a round of multilateral liberalization has two effects on the total profits made by a firm from Country X. First, MTL reduces the profits that domestic firms make in the domestic market. This loss depends positively on the number of firms in the two other countries, but negatively on the degree of preference between $X$ and $Y$. Second, M TL (which, by definition, also involves tariff reduction by all trading partners) increases the profits made in the rest of the world because of improved market access. The size of this increase depends positively on the number of firms of the importing countr y. But Country X's profit gains in Y's market are negatively related to the degree of preference in the PTA.

Outside the PTA, the total profits of the representative firm in the excluded country (Country Z) are written as: 


$$
\begin{aligned}
z & (,)=\left\{\frac{\left(A_{X}-c\right)-\left(n_{X}+n_{Y}+\mathbb{1} 1-\right) t_{X}}{n+1}\right\}^{2} \\
& +\left\{\frac{\left(A_{Y}-c\right)-\left(n_{X}+n_{Y}+1\right)(1-) t_{Y}}{n+1}\right\}^{2} \\
& +\left\{\frac{\left(A_{Z}-c\right)+\left(n_{X}+n_{Y}\right)(1-) t_{Z}}{n+1}\right\}^{2} .
\end{aligned}
$$

The first (resp. second and third) term on the RHS represents the profits that a firm in Country $Z$ makes in X's (resp. in Y's and Z's) market. An increase in the degree of preference between $X$ and $Y$ reduces the profits that $Z$ 's producers make in those markets. This is the trade diversion effect of the PTA on Country $Z$. These profit losses depend positively on the number of firms in the PTA members. On the other hand, multilateral trade liberalization-an increase in $\gamma$-affects Z's firms in two ways. First, it leads to more domestic competition, which decreases the profits made in the local market. This loss is increasing in the number of firms producing in $X$ and $Y$, $n_{X}$ and $n_{Y}$. Second, since it entails better market access, M TL increases the profits made in the two foreign countries. The profit gains are positively related to the number of firms in $X$ and $Y$ because $Z$ 's firms improves their competitiveness vis-á-vis those firms. The gains also increase with the degree, $\alpha$, of preference in the PTA. The more they are discriminated against, the more Z's firms gain from multilateral tariff cuts.

\section{Regionalism and Its Effects on Multilateralism}

As was stated above, we would like to study effects of regionalism $(\alpha)$ on the different countries' incentives to undertake multilateral liberalization $(\gamma)$. Suppose that at the status-quo equilibrium, $\alpha$ and $\gamma$ are equal to zero. Then, the incentive of Country $i(i=X, Y$, or $Z)$ to participate in a round of multilateral trade liberalization $\gamma$ percent can be written as:

$$
{ }_{i}(0, \quad)-{ }_{i}(0,0)
$$

When this quantity is positive, Country i's firms are initially supporting multilateral liberalization. When it is negative, the firms are resisting multi- 
lateralism. The larger (or the less negative) this quantity is, the stronger the incentive (or the weaker the resistance) of Countr $y \mathrm{i}$ for agreeing to a multilateral tariff reduction of $\gamma$ percent.

Suppose now that $X$ and $Y$ establish a PTA and start giving each other $a$ preferential access of $\alpha$ percent, Country i's support for a round of MTL becomes:

$$
i(,)-{ }_{i}(, 0)
$$

A positive (negative) sign on this quantity means that Country i's firms support (resist) a multilateral liberalization of $\gamma$ percent. For the intent and purpose of this paper, what we are interested in is the sign of the difference between (2) and (3), which represents the change in Country i's support for (or resistance to) a M TL of $\gamma$ percent as a result of the establishment of the PTA of $\alpha$ percent:

$$
{ }_{i}(,)=\left[{ }_{i}(,)-{ }_{i}(, 0)\right]-\left[{ }_{i}(0,)-{ }_{i}(0,0)\right] .
$$

If the difference $\Delta_{i}(\alpha, \gamma)$ is positive, then one can say that the establishment of the PTA of $\alpha$ percent between $X$ and $Y$ increases Country i's support-or decrease its resistance-for a M TL of $\gamma$ percent. If the expression is negative, then the PTA makes Country i less willing to liberalize multilaterally.

It is important to note at this point that a negative $\Delta_{i}(\alpha, \gamma)$ could just be the result of a move from a positive incentive to a less positive incentive-a decrease in support. In that case, it does not necessarily imply that the country would reject the given level of M TL following the PTA. Similarly, a positive $\Delta_{i}(\alpha, \gamma)$ could just be the result of a move from a negative incentive to a less negative incentive-a decrease in resistance. In that case, it does not necessarily imply that the country would accept the given level of M TL following the PTA. In the remainder of the paper, the phrases "increased (decreased) support" or "increased (decreased) incentive" are used broadly enough to include "decreased (increased) resistance".

For any parameter values, one could compute $\Delta_{i}(\alpha, \gamma)$ for each of the three countries. However, for ease of presentation and tractability, we will for now assume that the three countries are ex-ante identical: $A_{X}=A_{Y}=A_{Z}=A$ 
and $t_{X}=t_{Y}=t_{Z}=t$. F urther, $n_{X}=n_{Y}=n_{Z}=1$. In the next section, we discuss the implications of relaxing these assumptions and study how the introduction of asymmetries into the model affects the main result of the paper.

We can now study the effects of the PTA on the members' incentives for MTL. Again, we will focus on Country X-Country Y's case can easily be reproduced by analogy. For any given regional preference of $\alpha$ percent, the change in X's incentive to liberalize multilaterally by $\gamma$ percent can be simplified, after substantial manipulations, into the following expression:

$$
{ }_{x}(,)=-\frac{t \quad \cdot(2(A-c)-t \cdot(8-5)(2-))}{8} .
$$

Note that the term $\Delta_{X}=(\alpha, \gamma)$ is a decreasing function of $\gamma$ (and of $\alpha$ ). N ot also that it can be positive or negative. When it is positive (negative), then the introduction of a $\alpha$ percent preference within the PTA, increases (decreases) support for a $\gamma$ percent MTL. For a given level of preference $\alpha$, there is a cut-off level of multilateral liberalization, denoted $\gamma_{x}$, such that the support for smaller liberalization $\left(\gamma<\gamma_{X}\right)$ increases $\left(\Delta_{X}(\alpha, \gamma)>0\right)$, while the support for larger liberalization $\left(\gamma>\gamma_{X}\right)$ decreases $\left(\Delta_{X}(\alpha, \gamma)<0\right)$. That cut - off M TL level, defined at $\Delta_{X}(\alpha, \gamma)=0$, is given by:

$$
{ }_{x}=2-\frac{2(A-c)}{t \cdot(8-5)} \text {. }
$$

This cut - off level, $\gamma_{x}$, is decreasing in $\alpha$. Hence, the maximum level of M TL for which Country X's support increases (or X's resistance decreases) declines as the degree of preference within the PTA rises.

To get the intuition for this result, recall that a multilateral liberalization has two opposing effects on the profits of X's representative firm: it decreases the profits it makes domestically but increases the profits it makes abroad (in $Y$ and $Z$ 's markets). As the degree of preference rises, the profit gain from the M TL in $Y$ decreases and the profit loss in $X$ increases. This makes $X$ more reluctant to undertake large multilateral liberalization: the more preference $X$ gives and gets from $Y$, the less market access it is willing to give and get from $Z$

Figure 1 shows the changes in X's incentive to liberalize multilaterally by $\gamma$ (measured on the vertical axis) for any level of preference $\alpha$ (measured on 
Figure 1

\section{Change in Country $X$ 's Incentives}

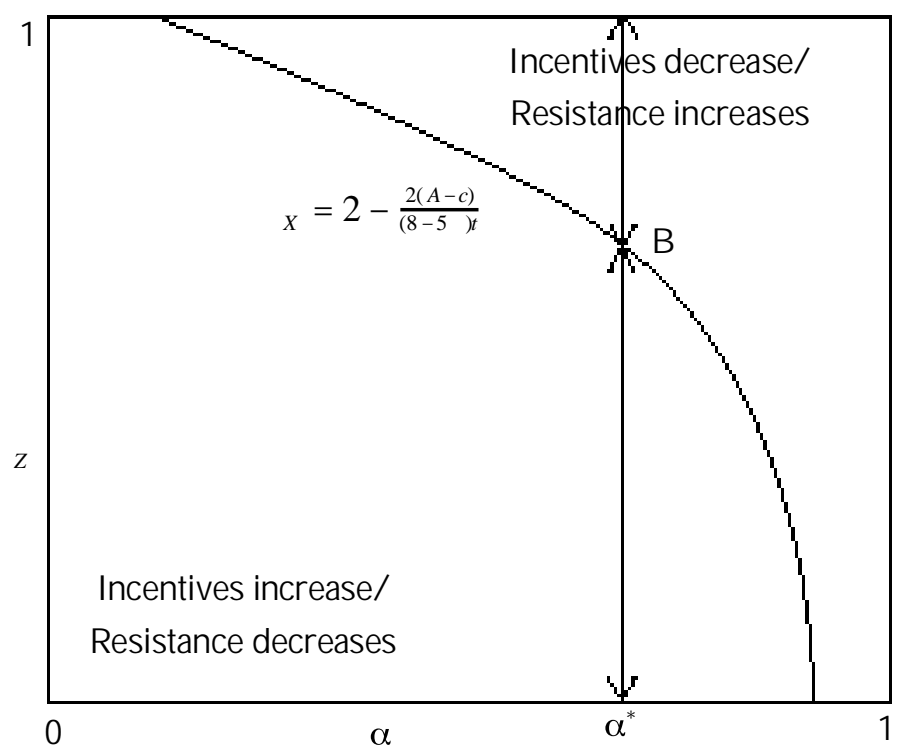

the horizontal axis) exchanged by $X$ and $Y$. The downward sloping curve, $\gamma_{X}$, gives, for each value of $\alpha$, the level of multilateral liberalization for which $X$ 's incentives are not affected by the given degree of preference. For any degree of preference between $X$ and $Y$, say $\alpha^{*}$ (in the graph), incentive to undertake a MTL of magnitude between 0 and $B$ percent increases (compared to the no-PTA status quo) while support for liberalization larger than $B$ decreases.

Outside the PTA, the change in Z's support for a round of multilateral tariff cuts of $\gamma$ percent for any given regional preference of $\alpha$ percent is given by:

$$
z(, \quad)=\frac{t \quad \cdot(2(A-c)-t \cdot(4+)(2-))}{8} .
$$

The expression $\Delta_{z}(\alpha, \gamma)$ is increasing in $\gamma$ (but decreasing in $\alpha$ ). For a given $\alpha$, there is a cut-off level of multilateral liberalization, denoted $\gamma_{z}$, such that Z's support for smaller liberalization $\left(\gamma<\gamma_{Z}\right)$ decreases $\left(\Delta_{Z}(\alpha, \gamma)<0\right)$, while its incentive for larger liberalization increases $\left(\Delta_{Z}(\alpha, \gamma)>0\right)$. That cutoff magnitude of $\mathrm{MTL}$, defined at $\Delta_{\mathrm{Z}}(\alpha, \gamma)=0$, is given by: 


\section{Figure 2}

\section{Change in Country Z's Incentives}

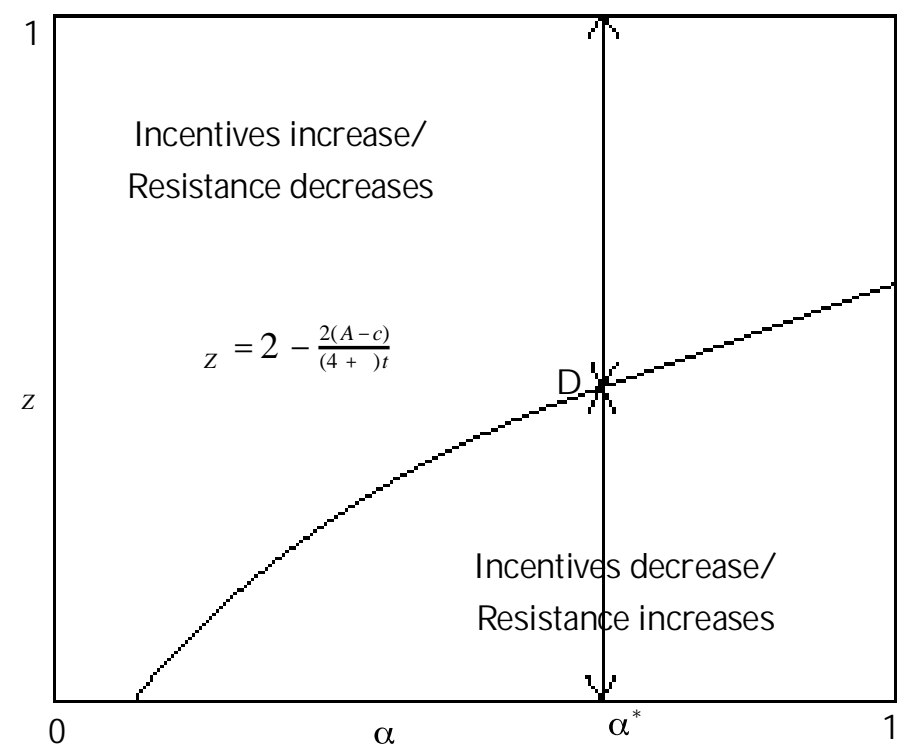

$$
z=2-\frac{2 A}{t .(4+)} \text {. }
$$

This level is increasing in the degree of preference in the PTA. Thus, the higher the degree of preference in the PTA, the higher is the minimum level of multilateral liberalization for which support increases (or resistance decreases) in the excluded country.

The intuition for this result is pretty simple. A M TL increases the profits that Z's representative firm makes in the PTA countries market, but decreases those made in the domestic market. An increase in the level of preference decreases the profit gain in $X$ and $Y$, but leaves unchanged the domestic profits. So the larger the degree of discrimination in the PTA, the smaller would be Country Z's support for small M TL. Small tariff cuts are not enough to offset Z's profit losses from the PTA's trade diversion effect.

Figure 2 shows this graphically. The upward sloping curve, $\gamma_{z}$, gives, for each value of $\alpha$, the level of multilateral liberalization for which Z's support are not affected by the PTA. The area below the curve represents the magnitudes of M TL for which Z's support decreases, while the area above repre- 
Figure 3

Impact of PTA on Incentives

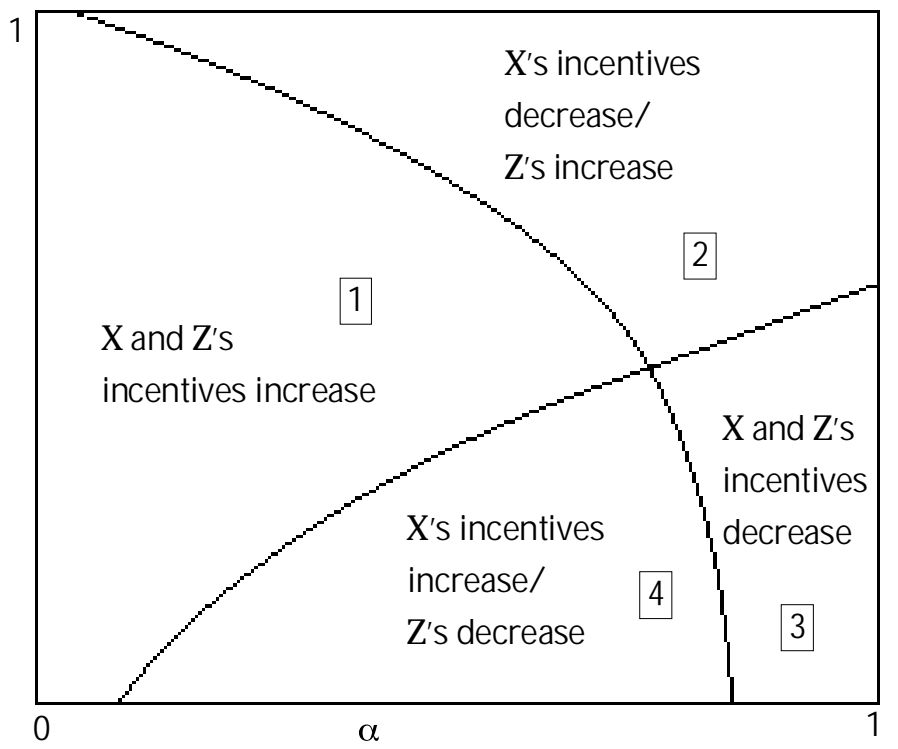

sents those for which incentive increases. For a given degree of preference between $X$ and $Y$, say $\alpha^{*}$, incentive to undertake multilateral liberalization between 0 and $D$ percent decreases (compared to the no-PTA status quo) while support for liberalization larger than $D$ increases.

Figure 3 brings the two curves $\left(\gamma_{X}\right.$ and $\left.\gamma_{Z}\right)$ together in the $(\gamma, \alpha)$ space. The triangular area towards the left of the figure (below $\gamma_{x}$ and above $\gamma_{Z}$ )denoted [1]-represents the "increased-support" levels of multilateral liberalization. For these levels of M TL, incentives in both PTA members and nonmember increase following the given level of preference within the PTA. The three other areas represent the "decreased-support" levels of multilateral tariff cuts. In area [2] (above $\gamma_{X}$ and $\gamma_{Z}$ ), $Z^{\prime}$ 's incentive increases but that of $X$ decreases. In area [3] (above $\gamma_{X}$ and below $\gamma_{Z}$ ), $X$ and $Z$ 's incentives both decrease. In area [4] (below $\gamma_{x}$ and $\gamma_{Z}$ ), $X$ 's incentive increases but that of $Z$ decreases.

From this analysis, one can easily reproduce Krishna's [1998] result - that regionalism can make initially feasible multilateral free trade infeasible. In fact, when $\alpha$ is small (i.e., discrimination is small), multilateral free trade $(\gamma=$ 


\section{Figure 4 \\ Comparative Statics}

a. Z's Number of Firms (higher $\delta$ )

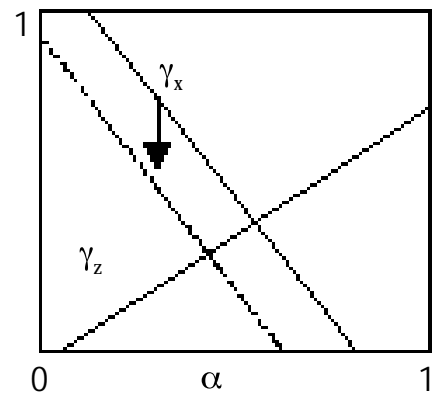

c. Tariffs (higher $\sigma$ or $\mathrm{t}$ )

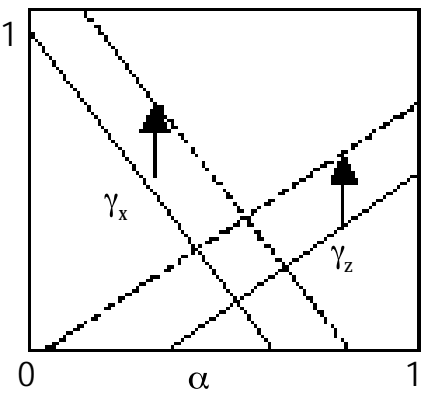

b. PTA's M arket Size (higher $\varepsilon$ )

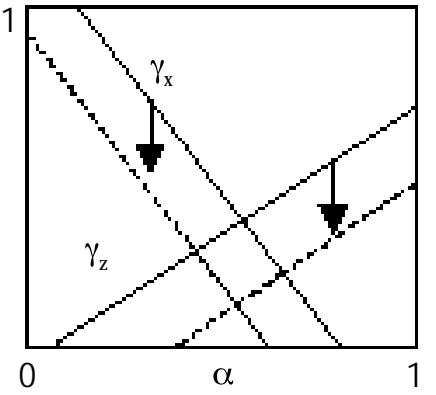

1) is in the "increased-support" set. But once $\alpha$ becomes large enough, it becomes in the "decreased-support" set. M ore generally in this model, the set of "increased-incentive" multilateral tariff cuts (i.e., the range of "morefeasible" M TL) shrinks both from below and from above as the degree of preference in the PTA increases. Ergo, we have shown in this simple model how regionalism can hinder incentive for multilateralism.

\section{Comparative Statics}

In the previous section, we carried out the analysis under the assumption that the three countries were identical. We are interested in how changes in the parameters of the model, or the introduction of asymmetries, affect the size of Area [1]-the "increased-incentive" set. F or tractability, we will contin- 
ue to assume that the PTA countries are still identical. This also allows us to focus the analysis on only one insider country. What we are interested in is the introduction of dissimilarities between the member countries and the excluded country. Hence, we assume that that $Z$ has $\delta$ times more firms than $X$ and $Y: n_{X}=n_{Y}=1$, and $n_{Z}=\delta$. Also, assume that $X$ and $Y$ 's markets are $\varepsilon$ times larger that $Z^{\prime} s$ ( $\varepsilon$ can be less than one): $A_{X}=A_{Y}=\varepsilon$. $A$ and $A_{Z}=A$. Further, $X$ and $Y$ 's tariffs are $\sigma$ times higher that $Z$ 's: $t_{X}=t_{Y}=\sigma . t$, and $t_{Z}=t$. Then, the expressions for the cut-off levels of MTL, $\gamma_{X}$ and $\gamma_{Z}$ become a bit more complicated than before:

$$
\begin{aligned}
& z=2-\frac{2 A(1+)-2 c}{t\left(2(5+3)-\left(5+4+{ }^{2}\right)\right)}, \text { and } \\
& z=2-\frac{2 A-2 c}{t(4+)} .
\end{aligned}
$$

These expressions allow us to conduct some comparative statics exercises. First, look at the effect of an increase in Z's number of firms (higher $\delta$ ). This shifts the curve $\gamma_{x}$ down (but does not affect $\gamma_{z}$ ) so that the "increasedincentive" set shrinks (Figure 4 a.). N ote that the amount of trade diversion due to the PTA is positive in $\delta$. The more firms $Z$ has, the stronger will be the competitive effects of multilateral trade liberalization-hence, the profit losses for the PTA members. Accordingly, for a given level of preference, the PTA members will be less willing to undertake large tariff cuts. In other words, the larger the trade diversion resulting from the PTA, the less likely it is that support for MTL increases. An implication of this is that small PTAs (in terms of the number of firms and relative to the rest of the world) are more reluctant to conduct large M TL.

Looking next at the PTA's market size $(\varepsilon)$, an increase in $X$ and $Y$ 's market size, shifts both $\gamma_{X}$ and $\gamma_{Z}$ downwards (Figure 4 b.). Countries $X$ and $Y^{\prime}$ 's support for large multilateral tariff cuts decreases because they are less willing to share their large markets with Z's producers. On the outside of the PTA, support for small M TL in $Z$ is higher, for higher $\varepsilon$, because the M TL will improve access to the larger PTA market. While the effects of an increase in $\varepsilon$ on the size of the "increased-incentive" set is ambiguous, it is clear that, when $X$ and $Y$ 's market size increases, large tariff cuts are more likely to experience decreased support (in member countries) while small 
tariff cuts are likely to experience increased support (in excluded countries) as a result of the PTA. The implication of this is that large PTAs (in terms of market size) are less willing to undertake large MTL. N ote that since the PTA does not affect the profits made in Z's market, the size of that market is not relevant for this result.

Similarly, because the profits made in Z's market is not affected by the PTA, changes in Z's tariffs do not affect $\gamma_{X}$ and $\gamma_{Z}$. Thus, an increase in $\sigma(X$ and $Y$ 's tariffs relative to $Z$ 's) or in $t$ (general level of initial tariffs for $X, Y$ and Z) would have the same effects. Such increase shifts both $\gamma_{X}$ and $\gamma_{Z}$ upwards (Figure 4 c.). Intuitively, higher initial tariffs increase everyone's profit gains from multilateral liberalization (even though they also increase domestic profit losses). For a given degree of preference, countries $X$ and $Y$ will be more willing to undertake large MTL when initial tariffs are high. Also, Country $Z$ will be inclined to undertake larger tariff cuts in order to lessen the negative effect of the PTA. While the effect of this on the size of the "increased-incentive" is ambiguous, it is clear that (some range of) higher multilateral tariffs cuts are likely to experience increased support.

\section{Conclusion}

Using a political economy model with imperfect competition, this paper shows how regionalism can affect the incentives for multilateralism. Our analysis departs from the literature on the subject matter by looking at the incentives of the excluded countries and by considering intermediate levels of trade liberalization.

Discriminatory trade policies alter the balance of gains and losses that the participating and non-participating countries experience from multilateral liberalization. As the degree of preference within the PTA increases, the insiders' support for large multilateral tariff cuts declines and the outsiders' support for small multilateral trade liberalization also declines. The set of "increased-incentive" multilateral tariff cuts (i.e., the range of MTL for which support increases following a given degree of preferential liberalization) shrinks as the degree of preference in the PTA increases. Ergo, regionalism can hinder incentives for multilateralism and there is a real possibility that the current proliferation of regional integration arrangements 
generates forces that would slow down efforts to achieve a more liberal multilateral trading system.

The willingness to undertake multilateral liberalization is also shown to depend on the size of the member countries (both in terms of market size, and in terms of number of firms). In terms of the number of firms, it was shown that small PTAs are more reluctant to conduct large M TL. However, when size is in terms of the domestic market, it is shown that it is the large PTAs that are less willing to undertake large M TL.

\section{Reference}

Andriamananjara, Soamiely [1999], "On the Size and Number of Regional Integration Arrangements: A Political Economy Model," World Bank Policy Research Working Paper 2117.

Bagwell, Kyle and Robert Staiger [1997], "M ultilateral Tariff Cooperation during the Formation of Regional Free Trade Areas," NBER Working Paper No. 4364.

Baldwin, Richard [1995], "A Domino Theory of Regionalism," NBER Work ing Paper N o. 4465.

Bhagwati, Jagdish and Arvind Panagariya [1996], "Preferential Trading Areas and M ultilateralism ---Strangers, Friends, or F oes?" in Bhagwati and Panagariya (eds.) The E conomics of Preferential Trade Agreements, The AEI Press, Washington, DC.

Bond, Eric W. and Constantinos Syropoulos [1996], "The Size of Trading Blocs, M arket Power and World Welfare Effects," Journal of Interna tional E conomics 40; pp. 411-437.

Brander, James and Paul Krugman [1983], "Reciprocal Dumping M odel of International Trade," Journal of International E conomics 15; pp. 313-321.

Cadot, Olivier, Jaime de M elo and M arcelo Olarreaga [1996], "Regional Integration and Lobbying for Tariffs against N on-members," CEPR Discussion Paper No.1448.

Cadot, Olivier, Jaime de M elo and M arcelo Olar reaga [1998], "Can Bilateralism Ease the Pains of Trade Liberalization," Paper Presented at the CEPR/ Venice International U niversity Workshop on Globalization, Regional Integration and Development, Venice J anuary 1998. 
Grossman, Gene and Elhanan Helpman [1995], "The Politics of F ree-Trade Agreements," American Economic Review, 85(4); pp. 667-90.

Krishna, Pravin [1998], "Regionalism and M ultilateralism: A Political Economy Approach," Quarterly Journal of Economics 113(1); pp. 227-51.

Krugman, Paul [1991], "Is Bilateralism Bad?" in Helpman, E., and A. Razin, (eds.) International Trade and Trade Policy, Cambridge: M IT Press.

Levy, Philip [1997], "A Political-economic Analysis of Free Trade Agreements," American E conomic Review 87(4); pp. 506-19.

Panagariya, Arvind and Ronald Findlay [1996], "A Political-Economy Analysis of F ree Trade Areas and Customs U nion," in Feenstra R., D. Irvin, and G. Grossman, (eds.), The Political Economy of Trade Reform, Essays in Honor of Jagdish Bhagwati, M IT Press.

Viner, Jacob [1950], "The Customs Union Issue," Carnegie Endowment for International Peace, New York.

Wei, Shang-J in and J effrey Frankel [1996], "Can Regional Blocs Be a Stepping Stone to Global Free Trade ? A Political Economy Analysis," International Review of E conomics and Finance, 5(4); pp. 339-347.

Winters, L. Alan [1996], "Regionalism versus M ultilateralism," World Bank Policy Research Working Paper 1687.

Yi, Sang-Seung [1996], "E ndogenous F ormation of Customs Unions under Imperfect Competition: Open Regionalism is Good," Journal of International E conomics 41; pp. 153-77. 